ISSN 1689-765X

\title{
Interpretation of Structural Parameters for Models with Spatial Autoregression**
}

JEL Classification: $C 21, C 51, J 64, R 11$

Keywords: spatial econometrics, measures of average impact, SAR model, SDM model, spatial autocorrelation

\begin{abstract}
The main purpose of the article is to consider a important issue of spatial econometrics, which is a proper interpretation of structural parameters of econometric models with spatial autoregression. The problem will be considered basing on the example of the spatial SAR model. Another purpose of the article is to make an overview of measures of average spatial impact proposed by the subject literature (see Lesage and Pace 2009). The analysis will include such measures as Average Total Impact to an Observation, Average Total Impact from an Observation, Average Indirect Impact to an Observation, Average Indirect Impact from an $\mathrm{Ob}$ servation and Average Direct Impact.

Having considered the above issues, I will introduce a set of three original measures that allow the interpretation of the strength of the impact of the explanatory processes within the spatial SAR model, which take the forms of average direct impact, average indirect impact and average induced impact. The use of this set of measures will be illustrated with the example of the analysis of the unemployment rate in Poland. It must be emphasized that the presented set of measures may also be designated for other spatial models. With the knowledge of the empirical form of the model and of the spatial weight matrix, the set of measures introduced simplifies
\end{abstract}

\footnotetext{
(C) Copyright Institute of Economic Research \& Polish Economic Society Branch in Torun Date of submission: February 8, 2013; date of acceptance: May 29, 2013

* Contact: michal.pietrzak@umk.pl, Uniwersytet Mikołaja Kopernika w Toruniu, Wydział Nauk Ekonomicznych i Zarządzania, ul. Gagarina 13a, 87-100 Toruń, Poland.

** The project was co-financed by Nicolaus Copernicus University in Toruń within a UMK research grant no. 1481-E.
} 
significantly the complex procedure of the interpretation of the structural parameters for spatial models to the use of merely three values.

\section{Introduction}

Spatial econometrics has been developing dynamically since the midnineteen-seventies and its problems have been discussed broadly in abundant literature around the world (see, Cliff, Ord 1973, 1981; Paelinck, Nijkamp1975; Klaassen et al. 1979, Paelinck, Klaassen 1979; Ripley 1981; Anselin 1988; Griffith 1988, 2003; Arbia 1989, 2006; Haining 1990, 2003; Cressie 1993; Anselin et al. 2004; LeSage, Pace 2004, 2009; Getis et al. 2004; Fischer, Getis 2004; Bivand et al. 2008). Economic spatial analyses constitute an important aspect in the practical use of the instruments of spatial econometrics. That is due to the fact that analyses performed frequently form the basis for determining the strategy for the spatial policy realized at the levels of local governments or the national government. Research conducted in that way covers a wide spectrum of phenomena, such as unemployment, salaries, migration of people, investment layouts, trade, economic growth, work efficiency, or innovation. An essential issue while conducting analyses is to provide a proper interpretation of causal processes for the spatial models obtained. Therefore, this article will focus on a proper assessment of the impact of the explanatory processes on the dependent process with the assumption of the existence of spatial dependency.

The article will consider the issue of a proper interpretation of structural parameters of models with spatial autoregression and the measures of average spatial impact proposed by the subject literature. After a granular analysis of the issues under consideration, original measures of average spatial impact will be introduced, and they are to be complementary in their character to the existing ones. The main advantage of the proposed measures is the ease with which they can be implemented practically. Due to that property, the measures can be applied by decision-makers at any level of management and can function as a useful instrument supporting the decision-making process. All the issues will be presented using the example of the $S A R$ model within the performed analysis of Poland's unemployment rate. The SAR model was selected due to its simplicity obtained as a result of the combination of the regression structure of explanatory processes and the spatial autoregression structure of the dependent process. All of the considerations presented in the article can be generalized and applied to other econometric spatial models, including the SDM model. 


\section{Spatial SAR Model and the Interpretation of Structural Parameters of the Model}

Consistently with the objective of the article, the spatial SAR model (Spatial Autoregressive Model) ${ }^{1}$ will be presented (see Anselin 1988; Arbia 2006; LeSage, Pace 2009). The SAR model described by equation (1) is a linear regression model enriched by the property of spatial autoregression. Spatial autoregression was introduced by the inclusion of spatial lags of the dependent process into the model ${ }^{2}$. These spatial lags describe the average impact of neighbors on the values of the dependent process obtained in a given region. The $S A R$ model is expressed as follows:

$$
\begin{gathered}
Y=\rho W Y+X \beta+\varepsilon \\
\varepsilon \sim N\left(0, \sigma^{2} I\right)
\end{gathered}
$$

where $Y$ is the vector of the value of the dependent process, $X$ is the matrix of explanatory processes, $\rho$ is the parameter of the spatial autoregression, $W$ is the spatial weight matrix, $\beta$ is the vector of structural parameters, and $\varepsilon$ represents the spatial white noise with a multivariate normal distribution ${ }^{3}$. The problem of the interpretation of structural parameters of spatial models was discussed by Anselin (2003), Abreu, de Groot, and Florax (2005) and LeSage and Pace (2009) ${ }^{4}$. The authors emphasized the fact that the existing autoregression in a spatial model necessitates another interpretation of the parameters of the model that is different from the interpretation applied in the case of a linear regression model ${ }^{5}$. If we present the matrix of explanatory processes by means of the aggregate of individual vectors,

\footnotetext{
${ }^{1}$ This model is also referred to in literature on spatial econometrics as "mixed-regressivespatial autoregressive model".

${ }^{2}$ It is also possible to introduce spatial autoregression into spatial white noise and, as a result, we can obtain the SEM model (see LeSage, Pace 2009).

${ }^{3}$ The designations introduced concern each equation included in the article. If a new designation is used for a equation, it will be described below that equation.

${ }^{4}$ In the article, I focused exclusively on the interpretation of structural parameters of spatial models. The issues related to spatial externalities, spill-over effect, global and local effects are not discussed in the article.

${ }^{5}$ The interpretation of the impact strength of the model parameters and the measures of average impact will be indicated within the present paper for the $S A R$ model. It must be noted, however, that in a situation when the impact of spatial lag of the explanatory process is significantly strong, then the estimates of parameters for the $S A R$ model will be incorrect. This will affect the quality of the interpretation of the impact strength since some of the values of the estimates of parameters for the $S A R$ model will be derived from the disregarded variables.
} 


$$
\begin{gathered}
Y=V(W) X \beta+V(W) \varepsilon, V(W)=(I-\rho W)^{-1}, \\
Y=V(W) \beta_{1} X_{1}+\ldots+V(W) \beta_{k} X_{k}+V(W) \varepsilon \\
S_{r}(W)=V(W) \beta_{r},
\end{gathered}
$$

we obtain the following form of the model ${ }^{6}$

$$
Y=\sum_{r=1}^{k} S_{r}(W) X_{r}+V(W) \varepsilon
$$

According to equation (6), for each explanatory process $X_{r}$ we obtain the matrix $S_{r}(W)$, whose individual elements determine the impact of the process $X_{r}$ on the dependent process depending on a selected spatial region. The matrix $S_{r}(W)$ can be expressed as follows:

$$
S_{r}(W)=\left[\begin{array}{cccc}
S_{r}(w)_{11} & \cdot & \cdot & S_{r}(w)_{1 n} \\
\cdot & & \cdot \\
\cdot & & & \cdot \\
S_{r}(w)_{n 1} & \cdot & \cdot & S_{r}(w)_{n n}
\end{array}\right] .
$$

In the case of spatial models it seems necessary to differentiate between the general and detailed interpretation of structural parameters. The detailed interpretation will be used in the meaning of the interpretation of the impact which requires the indication of two locations: the region in which the change in the explanatory process occurred and the region in which the change in the dependent process occurred. With such a formulation of the definition, each element of the matrix $S_{r}(W)$ will constitute a detailed interpretation of the model.

That means that there exists a possibility of overinterpretation, if the model is not specified appropriately. A model that additionally considers the impact of spatial lags of the explanatory process is the spatial Durbin model (SDM) (see. LeSage, Pace 2009). In the case when the specification of the $S D M$ model is assumed, it is necessary to consider in the formulas applied in the paper the impact of spatial lag of the explanatory process.

${ }^{6}$ Symbols used to describe equations (3)-(7) correspond to the symbols applied in the work by LeSage and Pace (2009). 
What is meant by the general interpretation is the interpretation where the requirement of the indication of two spatial locations will be limited. The limitation may concern either the location $i$ or $j$, or both of them, which generates various general interpretations ${ }^{7}$. That is a significant difference if compared with the linear regression model where the estimates of structural parameters allow an immediate general interpretation ${ }^{8}$.

Therefore, in the model there are $n^{2}$ of various detailed interpretations of the impact of the process $X_{r}$, depending on the selected spatial locations. The selected value $S_{r}(W)_{i j}$ is interpreted as an average impact of the change in the process $X_{r}$ which occurred in the region $i$, on the value of the dependent process in the region $j$ and that can be described by means of the following equation:

$$
\partial E\left(Y_{j}\right) / \partial x_{i r}=S_{r}(W)_{i j}
$$

\section{Measures of Average Impact Applied in the Explanatory Processes of the Model}

A practical application of the spatial model appears to be complex, due to the existence of the number $n^{2}$ of detailed interpretations. The solution to this problem is averaging the selected set of detailed interpretations of the model. The result of this operation is the obtainment of the measures of average spatial impact, which allow the general interpretation of the model. Such measures were proposed by LeSage and Pace (2009). In their publication, spatial impact was split into two effects. The first of the distinguished effects was the direct effect understood as the total impact of the explanatory process of the location $i$ on the dependent process at the same location. The indirect effect, in turn, was described as the total impact of the explanatory process at the location $\mathrm{i}$ on the dependent process at different locations. The direct effect is expressed by the value $\boldsymbol{S}_{\boldsymbol{r}}(\boldsymbol{W})_{\boldsymbol{i} j}$ for $i=j$, and the indirect

${ }^{77}$ For example, we may assume how a change in the explanatory process at any location impacts averagely the change the dependent process at a specific location, or how a change in the explanatory process at a specific location impacts averagely the change in the dependent process at any location.

${ }^{8}$ In the case of a linear regression model it is not necessary to consider spatial location of areas. The interpretation of the model is a general interpretation and is universal for all regions. This results from the limitations of a linear regression model within which it is assumed that a dependent variable may be changed only in the area in which the explanatory variables were changed. 
effect is expressed by the value $\boldsymbol{S}_{\boldsymbol{r}}(\boldsymbol{W})_{\boldsymbol{i} \boldsymbol{j}}$ for ${ }^{i \neq j}$. Next, taking into account the direct and indirect effects, the authors proposed five measures of average spatial impact. The result of the calculation of such a measure is the obtainment of one value that can be easily referred to as the general interpretation of average impact of the explanatory process conducted for any location 9 .

The first measure proposed by LeSage and Pace (2009) is Average Total Impact to an Observation $A_{T}^{t}$. That measure expresses an average change in the dependent process in a selected location caused by a change in the explanatory process $X_{r}$ in all locations happening simultaneously. The measure is calculated as an average for the aggregate of all rows of the matrix $S_{r}(W)$ and may be expressed as follows:

$$
A_{T}^{t}=n^{-1} l_{n}^{\prime} S_{r}(W) l_{n},
$$

where $n$ is the number of analyzed regions and $l_{n}$ is the constant term vector of ones.

The second measure is Average Total Impact from an Observation $A_{T}^{f}$. That measure expresses an average change in the dependent process in all locations simultaneously and caused by a change in the explanatory process $X_{r}$ in a selected location. The measure is calculated as an average for the aggregate of all columns of the matrix $S_{r}(W)$ and may be expressed also by equation (9).

The third measure is Average Direct Impact $A_{D}$, which expresses an average value of the change in the dependent process in any location impacted by the explanatory process $X_{r}$ of the same location. The measure is calculated as an average of all values $S_{r}(W)_{i j}$ when $i=j$ and may be expressed by the following equation ${ }^{11}$ :

$$
A_{D}=n^{-1} \operatorname{tr}\left(S_{r}(W)\right) \text {. }
$$

The fourth measure is Average Indirect Impact to an Observation $A_{I}^{t}$. The measure expresses an average change in the dependent process in a freely selected location caused by a change in the explanatory process $X_{r}$ in all locations with the exclusion of the selected one. The measure is calculated as

\footnotetext{
${ }^{9}$ Spatial impact for any location will be precised within the measures presented.

${ }^{10}$ Symbols used for the measures were developed by me for the purposes of this article.

${ }^{11}$ The $t r$ symbol represents the trace of the matrix.
} 
the difference between the average total impact to an observation and the average direct impact which can be described as follows:

$$
A_{I}^{t}=A_{T}^{t}-A_{D}
$$

The last measure is Average Indirect Impact from an Observation $A_{I}^{f}$. This measure expresses an average impact caused by a change in the explanatory process $X_{r}$ in a selected location on the value of the dependent process in all locations with the exclusion of the selected one. The measure is calculated as the difference between the average total impact to an observation and the average direct impact which can be described as follows:

$$
A_{I}^{f}=A_{T}^{f}-A_{D}
$$

The measures presented result from the averaging of selected detailed interpretations. Properly selected values, with the consideration of the direct and indirect impacts, led to the obtainment of explicit measures of spatial impact. Average Total Impact, Average Direct Impact, and Average Indirect Impact convey abundant information when areas within the whole economic system are being considered. In addition, the measures are valuable as instruments for decision-makers, since they inform how a change in the explanatory process in a selected area, or in a few of them, impacts spatially the whole region.

The analysis of the spatial average impact measures proposed by subject literature served as a reference point for the introduction of the new measures. The new measures are to complement the already existing ones. The basis for the consideration of the new, original set of measures comprised questions on how a change in the explanatory process in a selected area:

- impacts the change in the dependent process in the same location,

- impacts the change in the dependent process in the first-order neighboring locations, ${ }^{12}$

- impacts the change in the dependent process in all the remaining locations.

The answers provided to the above questions were to help in creating measures that would allow for working out easy and universal practical applications. In order to obtain answers to the questions asked another classification of impact effects was taken into account. That classification was pre-

${ }^{12}$ The spatial neighborhood is used here in the sense of contiguity. 
sented by Abreu, de Groot, and Florax (2004) ${ }^{13}$. The authors distinguished the direct effect that is equal in each region to the estimate of the parameter $\beta_{r}$ of the model, the indirect effect related to the matrix of the first-order neighborhood, and the induced effect related to the matrixes with the order of neighborhood of a higher order. According to that classification, the total effect can be presented by the equation where each of the effects is inserted subsequently in square brackets.

$$
\partial E(Y) / \partial x_{r}=\left[I \beta_{r}\right]+\left[q W \beta_{r}\right]+\left[q^{2} W^{2} \beta_{r}+q^{3} W^{3} \beta_{r}+\ldots\right]
$$

The classification of spatial impact effects shown by equation (13) differs from the classification proposed by LeSage and Pace (2009). The direct impact $^{14}$ was described as the impact of the explanatory process in the location $i$ on the dependent variable of the same location, although without the consideration of any further impacts resulting from the existence of spatial dependency. The indirect impact was explained as the impact of the explanatory process on the values of the dependent process in the first-order neighborhood location, and the induced impact measures the strength of the impact in locations with the order of neighborhood that is higher than the first-order neighborhood. In the case of the indirect impact, spatial impacts of higher orders are not taken into account as well.

The two classifications described constituted a starting point for establishing the new classification. In this article, I want to propose an alternative division (to the two mentioned) into the direct effect, the indirect effect, and the induced effect. The direct effect is described in an identical way as in the work by LeSage and Pace (2009), as the average impact resulting from a change in the explanatory process in a selected region $i$ on the dependent process of the same location with the consideration of all impacts resulting from spatial dependency. The indirect effect is defined as an average impact resulting from a change in the explanatory process in the region $i$ on the dependent process in the region that is adjacent to region $i$ in the sense of the first-order neighborhood. For the induced effect the average change in the explanatory process is determined for the neighboring regions with the order of neighborhood that is higher than the first-order neighborhood. All impacts resulting from the spatial dependency are considered for both the indirect effect and the induced effect.

${ }^{13}$ The problem of spatial impact effects was also discussed by Ward and Kristian (2008), Kelejian, Murrell and Shepotylo (2008).

${ }^{14}$ The direct impact defined in that way equals the value of the structural parameter $\beta_{r}$ of the model. The direct impact as defined in the work by LeSage and Pace (2009) is understood in a broader sense. It considers also the impacts resulting from the existing spatial dependency which affects its greater value. 
The proposed alternative classification of the effects of spatial impact, together with the questions formulated for the measures, was useful for the reconsideration of the measures of average impact and enabled me to propose a new set of three measures. The set is composed of the Average Direct Impact $A_{D}$, Average Indirect Impact $A_{I}$, and Average Induced Impact $A_{R}$. The measures were constructed in such a way to allow an easy and explicit interpretation of the impact of a selected explanatory process $X_{r}$. The three measures correspond to the direct effect, the indirect effect and the induced effect respectively. The measure of the average direct impact $A_{D}$ allows a general interpretation of the impact of the selected explanatory process $X_{r}$ on the economic phenomenon being analyzed with the assumption that the change occurred precisely in that region. The measure of the average indirect impact $A_{I}$ allows a general interpretation of the impact when the change in the explanatory process occurred in the first-order neighboring region and the measure of the average induced impact $A_{R}$ is applied in the case of changes in the neighboring regions with the order of neighborhood that is higher than the first-order neighborhood. The measures will be given a more detailed consideration in the further parts of the article.

The measure of the Average Direct Impact $A_{D}$ was described earlier by means of equation (10). The measure of the Average Indirect Impact $A_{I}$ expresses an average change in the dependent process in a freely selected location caused by a change in the explanatory process $X_{r}$, provided that the change in the process $X_{r}$ occurred in the location that is neighboring (in the sense of the first-order neighborhood) the selected one. The measure is calculated as an average for all the averages worked out for all rows. However, an average calculated for a given row $i$ is obtained only from the elements being the first-order neighbors to the location $i$. The measure can be described as follows:

$$
A_{I}=n^{-1} \operatorname{tr}\left(W * S_{r}(W)^{T}\right)
$$

The measure of the Average Induced Impact $A_{R}$ describes an average change in the dependent process in a freely selected location caused by a change in the dependent process $X_{r}$, provided that the change in the dependent process $X_{r}$ occurred in a location neighboring (with higher than the first-order neighborhood) the selected one. The measure is also calculated as an average for all the averages worked out for all rows. An average calculated for a given row $i$ is obtained only from the elements that have higher than the first-order neighborhood to the location $i$. The measure can be described as follows: 


$$
\begin{gathered}
A_{R}=n^{-1} \operatorname{tr}\left(G * S_{r}(W)^{T}\right) \\
F=\mathbf{1}-I-W_{B},
\end{gathered}
$$

where 1 is the matrix of ones, $I$ is the identity matrix, $W_{B}$ is the first-order neighborhood binary matrix, and $G$ is the matrix $\mathrm{F}$ having row sums normalized.

\section{Detailed Interpretation of Structural Parameters Within a Spatial Analysis of the Unemployment Rate}

The interpretation of structural parameters of the spatial $S A R$ model and the use of the proposed measures of average spatial impact will be conducted based on the econometric analysis of Poland's unemployment rate in 2009 made by poviats (NUTS 4$)^{15}$. Figure 1 presents the differentiation of the phenomenon of the unemployment in poviats in accordance with the accepted level of aggregation.

Figure 1. Poland's unemployment rate (2009, NUTS 4)

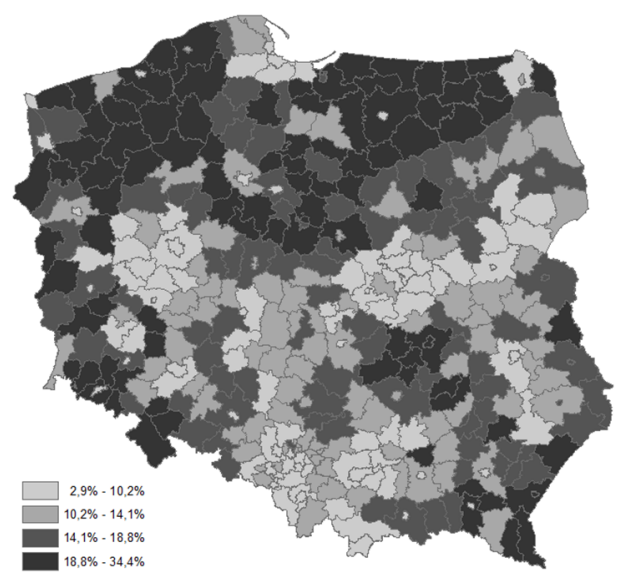

Source: Authors' compilation.

${ }^{15}$ Different NUTS levels will be used within the presentation of the results of the analysis conducted. Poland as a country (NUTS1) is divided into 16 voivodships (NUTS2) which are composed of a total of 379 poviats (NUTS4). The estimation of the model is based on the data from poviats as are any other calculations made for the purposes of the article. 
The research conducted on the spatial distribution of the unemployment rate indicates the occurrence of clusters of areas characterized by a high unemployment level and of clusters of areas characterized by a low unemployment level, which proves a positive spatial dependency of the considered phenomenon. Including this information in the spatial model with the form of autoregressive component increases the value of the such models.

The estimation of the spatial SAR model was made within the conducted analysis. The unemployment rate was taken for the dependent process, and the levels of investment outlays made in enterprises $X_{I}$ and the number entities of the national economy $X_{2}$ were taken for the explanatory processes. Both the levels of investment outlays made in enterprises and the number entities of the national economy were calculated as per capita ${ }^{16}$. The results obtained from the estimation of the model ${ }^{17}$ are shown in Table 1.

The model is characterized by a high positive value of the autoregression parameter reaching 0.67 , which indicates the existence of a strong spatial dependency characterizing the phenomenon of unemployment. The estimates of the structural parameters have negative designations, which indicates a negative causal dependency of the unemployment rate on the accepted explanatory processes. A proper economic interpretation of the impact of the causes of the unemployment phenomenon means the correctness of the accepted specification of the spatial SAR model. The value of the coefficient of determination $\left(\mathrm{R}^{2}\right)$ equals $52 \%$ and indicates a satisfactory fit of the models to the empirical data ${ }^{18}$. The obtained value of Moran's $I$ statistics at the level of 0.008 does not allow the rejection of the null hypothesis which is about the lack of the autocorrelation of residuals. The estimates of the parameters of the explanatory processes amount to -0.425 for the investment outlays made in enterprises, and -0.472 for the number of entities. However, the existence of the spatial dependency in the model compels the consideration of the interpretation of structural parameters in a detailed way with the application of the $S_{r}(W)$ matrix. Also, it is possible to apply average impact measures and move on to a general interpretation of the model.

${ }^{16}$ The unit applied in the first process is one thousand zlotys per capita and in the second process 100 economic entities per every 10,000 inhabitants.

${ }^{17}$ All the calculations presented in the article were made in the R-CRAN program.

18 The majority of the spatial economic analyses conducted by me indicated the existence of a strong correlation of causal processes. The correlation became even stronger when the level of the aggregation of spatial processes increased. This is a significant problem of the stage of the specification of the econometric spatial model due to the elimination of the part of the explanatory processes selected properly, in the sense of causality, which merely duplicate information resulting from other processes. The explanatory processes determined initially were reduced, in most cases, to one, sometimes to two processes which obviously affect the lower level of the $R^{2}$. 
Table 1. The results of the estimation of the SAR and SDM models for the unemployment rate ${ }^{19}$

\begin{tabular}{|c|c|c|c|c|}
\hline Parameters & Estimates & $\mathrm{p}$-value & Estimates & p-value \\
\hline$\rho$ & 0.67 & $\sim 0.00$ & 0.68 & $\sim 0.00$ \\
\hline$\beta_{0}$ & 9.71 & $\sim 0.00$ & 9.74 & $\sim 0.00$ \\
\hline$\beta$ & -0.42 & $\sim 0.00$ & -0.42 & $\sim 0.00$ \\
\hline$\beta_{2}$ & -0.47 & $\sim 0.00$ & -0.49 & $\sim 0.00$ \\
\hline$\beta_{3}$ & & & 0.0006 & 0.57 \\
\hline$\beta_{4}$ & & & 0.0001 & 0.76 \\
\hline Moran's I statistics & 0.008 & 0.37 & 0.004 & 0.41 \\
\hline$R^{2}$ & & 0.52 & & 0.52 \\
\hline Logarithm of the likeli & ood function & -1099.97 & & -1099.61 \\
\hline
\end{tabular}

Source: Authors' compilation.

In the next step, based on the spatial neighborhood matrix and the estimates of the parameters of the model, the $S_{1}(W)$ and $S_{2}(W)$ matrixes were designated and they included all the detailed interpretations of the model. In order to present the application of the selected detailed interpretations in a spatial analysis, two scenarios were taken into account. In the first scenario, the problem considered was how Poland's unemployment rate is affected by an increase in the explanatory processes by one unit in a given area of the Torun poviat. That means assuming the increase in investment outlays of 1000 PLN per capita and an increase in the number of economic entities amounting to 100 per every 10000 inhabitants of Torun. The other scenario assumes a rise in the level of the explanatory processes of one unit in two poviats simultaneously in Torun and Bydgoszcz ${ }^{20}$. Figure 2 presents the

${ }^{19}$ The estimation was performed for the following specifications of spatial models designated by the equations, the SAR model $Y=\rho W Y+\beta_{1} X_{1}+\beta_{2} X_{2}+\varepsilon$ and the $S D M$ model: $Y=\rho W Y+\beta_{1} X_{1}+\beta_{2} X_{2}+\beta_{3} W X_{1}+\beta_{4} W X_{2}+\varepsilon$. Variables $X 1, X 2$ correspond to the explanatory processes mentioned. In the case of the SDM model, the impact of spatial lags of the explanatory process proved statistically invalid (parameters $\beta 3, \beta 4$ ). Also, the logarithm of the likelihood function does not indicate any better adjustment to empirical data of the $S D M$ model in comparison with the SAR model. In accordance with the above, the interpretation of the impact strength of the model parameters and of measures of average impact will be designated for the $S A R$ model.

${ }^{20} \mathrm{I}$ am interested particularly in the poviats of the Kujawsko-Pomorskie voivodship. Two poviats were selected for the purpose of conducting the spatial impact analysis (Torun and 
poviats selected from the following voivodships: Kujawsko-Pomorskie, Pomorskie, Wielkopolskie, Lódzkie, Mazowieckie and WarminskoMazurskie $^{21}$. The Torun poviat and its first-order and second-order neighbors were distinguished ${ }^{22}$. Figure 3 shows the Bydgoszcz poviat and the areas which are its first-order and second-order neighbors ${ }^{23}$. The figures were developed to make the understanding of the further calculations easier.

The impact relative to the change in the level of the explanatory processes is the strongest in the poviats where that change occurred, that is in Torun and Bydgoszcz, and then the impact becomes weaker when the order of neighborhood grows. Figure 4 presents the poviats of the KujawskoPomorskie voivodship together with their names ${ }^{24}$. The analysis of Figure 2 and Figure 4 will allow a better understanding of the impacts within scenario 1; however, for scenario 2 it is necessary to analyze Figure 2, Figure 3 and Figure 4 at the same time. In the case of scenario 2, subsequent variants are considered as proper order neighbors for the two poviats (Torun and Bydgoszcz) simultaneously.

Bydgoszcz). These two poviats were selected due to the fact that they constitute the two major centers contributing to the development of the voivodships.

${ }^{21}$ Torun and Bydgoszcz are poviats (NUTS 4) that belong to the Kujawsko-Pomorskie voivodships (NUTS 2). To make the figures clear enough the poviats presented were limited to the following voivodships: Kujawsko-Pomorskie, Pomorskie, Wielkopolskie, Lódzkie, Mazowieckie and Warminsko-Mazurskie.

${ }^{22}$ The neighborhood was defined based on the criterion of the common border (contiguity). It must be emphasized that Torun and its first-order neighbors are also its second-order neighbors. This results from the fact that the same area may be a neighbor of various orders. However, what is essential in the interpretation of the spatial impact for the selected poviats is the poviat's lowest order of neighborhood relative to Torun.

${ }^{23}$ In the case of establishing the order of neighborhood for Torun and Bydgoszcz an essential problem occurred and I undertook to solve it. The Torun poviat is contained in the Torunski poviat and the Bydgoszcz poviat is contained in the Bydgoski poviat. This results from the administrational division and means that according to the criterion of the common border Torun and Bydgoszcz possess one neighbor each. Actually, Torun and Bydgoszcz constitute the two largest towns of the Kujawsko-Pomorskie voivodship and their impact on the neighbors of the Torunski and Bydgoski poviats is stronger than in the case of the poviats under consideration. In addition, it is planned to create the Torun-Bydgoszcz agglomeration in the future. Therefore, while building the spatial weight matrix an exception was made and the Torunski poviat together with its first-order neighbors were recognized as the first-order neighbors of Torun and, similarly, the Bydgoski poviat and its neighbors were treated as the neighbors of Bydgoszcz. I finds it as an example of the situation when during building of the spatial neighborhood matrix it is necessary to consider first the economic aspects of the researched issue. The problem concerns a bigger number of Polish poviats and similar measures were taken for them.

${ }^{24}$ To keep the figure transparent, Figure 4 contains only some of the poviats presented in Figure 2 and Figure 3. 
Figure 2. First-order and second-order neighborhoods for the Torun poviat

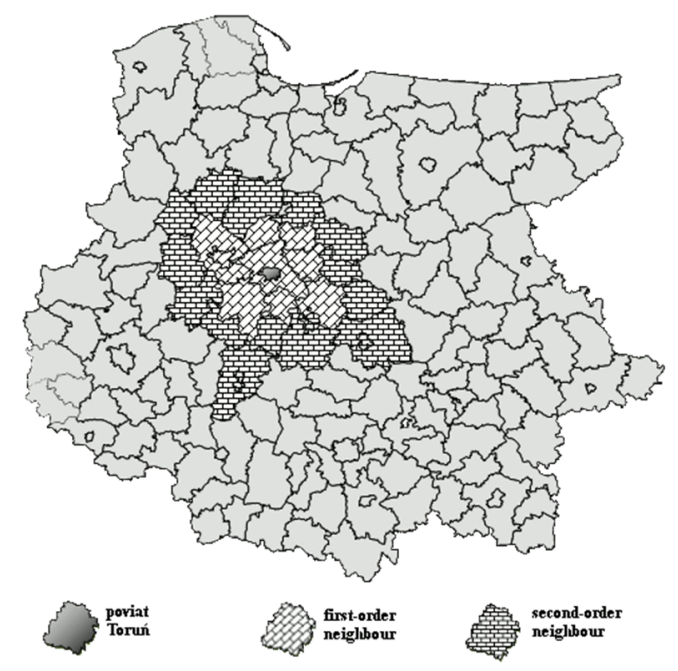

Source: Authors' compilation.

Figure 3. First-order and second-order neighborhoods for the Bydgoszcz poviat

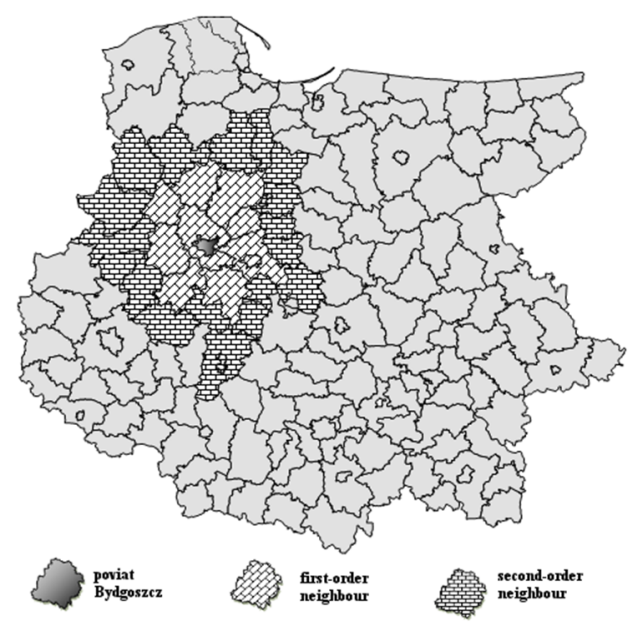

Source: Authors' compilation. 
Figure 4. Poviats of the Kujawsko-Pomorskie voivodship

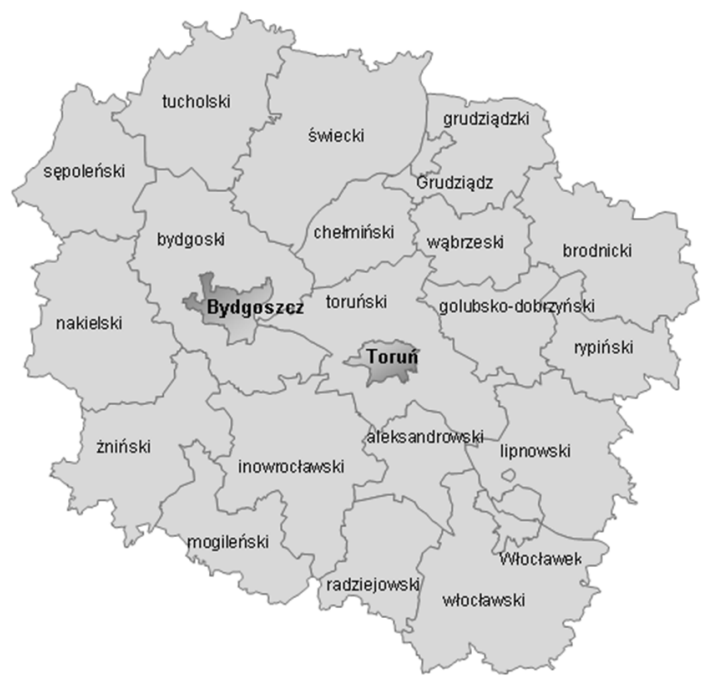

Source: Authors' compilation.

As was assumed in scenario 1, one column was selected from each of the obtained matrixes $S_{1}(W)$ and $S_{2}(W)$. The columns that were selected contained detailed interpretations of the impact of the Torun poviat on all the remaining poviats. Each element of the corresponding column constitutes Torun's potential impact exerted on a suitable poviat resulting from the change in the process $X_{1}$ or in the process $X_{2}$.

The results of the calculations made for scenario 1 are presented in Table 2. It shows subsequent effects of the impact of Torun on the selected poviats relative to the change in investment outlays by one unit and to the change in the number of economic entities by one unit as well as the total effect of the impact for the two explanatory processes. Table 2 contains the results obtained for all the poviats of the Kujawsko-Pomorskie voivodship and for some selected poviats of the Dolnoslaskie voivodship and Lubelskie voivod$\operatorname{ship}^{25}$. For other poviats the effect of the impact was close to zero since the places where the changes occurred were too distant ${ }^{26}$.

${ }^{25}$ That means that only the elements selected from the previously determined columns are presented.

${ }^{26}$ The number of poviats amounts to 379 and if all of them were to be displayed Table 2 would have to contain 380 rows. 
Table 2. Impact of the change in the level of investment outlays and the number of economic entities in Torun on the unemployment rate in the analyzed poviats

\begin{tabular}{|c|c|c|c|c|}
\hline \multirow[b]{2}{*}{ Poviat } & \multirow[b]{2}{*}{ Voivodship } & \multicolumn{3}{|c|}{ Effect of impact } \\
\hline & & $\begin{array}{c}\text { Investment } \\
\text { outlays }\end{array}$ & $\begin{array}{c}\text { Number of } \\
\text { entities }\end{array}$ & $\begin{array}{r}\text { Total } \\
\text { effect }\end{array}$ \\
\hline Legnica & DolnoSlaskie & 0.000 & 0.000 & 0.000 \\
\hline Wroclaw & DolnoSlaskie & 0.000 & 0.000 & 0.000 \\
\hline Aleksandrowski & Kujawsko-Pomorskie & -0.073 & -0.081 & -0.155 \\
\hline Brodnicki & Kujawsko-Pomorskie & -0.020 & -0.023 & -0.043 \\
\hline Bydgoski & Kujawsko-Pomorskie & -0.055 & -0.060 & -0.115 \\
\hline $\begin{array}{l}\text { Chelminski } \\
\text { Golubsko- }\end{array}$ & Kujawsko-Pomorskie & -0.074 & -0.082 & -0.155 \\
\hline Dobrzynski & Kujawsko-Pomorskie & -0.076 & -0.085 & -0.161 \\
\hline Grudziadzki & Kujawsko-Pomorskie & -0.019 & -0.021 & -0.040 \\
\hline Inowroclawski & Kujawsko-Pomorskie & -0.059 & -0.065 & -0.123 \\
\hline Lipnowski & Kujawsko-Pomorskie & -0.023 & -0.026 & -0.049 \\
\hline Mogilenski & Kujawsko-Pomorskie & -0.013 & -0.014 & -0.027 \\
\hline Nakielski & Kujawsko-Pomorskie & -0.017 & -0.019 & -0.036 \\
\hline Radziejowski & Kujawsko-Pomorskie & -0.021 & -0.023 & -0.044 \\
\hline Rypinski & Kujawsko-Pomorskie & -0.018 & -0.020 & -0.038 \\
\hline Sępolenski & Kujawsko-Pomorskie & -0.013 & -0.015 & -0.028 \\
\hline Swiecki & Kujawsko-Pomorskie & -0.018 & -0.020 & -0.039 \\
\hline Torunski & Kujawsko-Pomorskie & -0.072 & -0.080 & -0.152 \\
\hline Tucholski & Kujawsko-Pomorskie & -0.017 & -0.019 & -0.035 \\
\hline Wabrzeski & Kujawsko-Pomorskie & -0.082 & -0.091 & -0.172 \\
\hline Wloclawski & Kujawsko-Pomorskie & -0.012 & -0.013 & -0.026 \\
\hline Zninski & Kujawsko-Pomorskie & -0.020 & -0.022 & -0.042 \\
\hline Bydgoszcz & Kujawsko-Pomorskie & -0.055 & -0.060 & -0.115 \\
\hline Grudziadz & Kujawsko-Pomorskie & -0.013 & -0.014 & -0.026 \\
\hline Torun & Kujawsko-Pomorskie & -0.468 & -0.519 & -0.987 \\
\hline Wloclawek & Kujawsko-Pomorskie & -0.012 & -0.013 & -0.025 \\
\hline Bialski & Lubelskie & 0.000 & 0.000 & 0.000 \\
\hline Bilgorajski & Lubelskie & 0.000 & 0.000 & 0.000 \\
\hline
\end{tabular}

Source: Authors' compilation. 
While interpreting the results shown in Table 2 it is necessary to refer to the linear regression model first. In the case of this model, if a change in the unemployment rate was to occur, it would be only in the Torun poviat. This is due to the fact that in a linear regression model is not considered the spatial dependency. With the SAR model, which in turn considers spatial dependency, changes in the unemployment rate occur also in other poviats.

The largest decrease in the unemployment rate can be seen in Torun, exactly where the change in the explanatory processes took place and where the direct effect occurred. The fall in the unemployment rate in Torun caused by the process $X_{1}$ is $0.468 \%$ and by the process $X_{2}$ is $0.519 \%{ }^{27}$. The total impact of the explanatory processes amounts to $-0.987 \%$. The change of value of the explanatory processes in Torun impacts also other poviats. The biggest change of the unemployment rate can be seen in the poviats that are first-order neighbors of Torun. In the case of some first-order neighbors of Torun, for instance the Bydgoski, Torunski and Chelminski, the fall in the unemployment rate caused by a change in the process $X_{I}$ is $0.072 \%, 0.055 \%$ and $0.074 \%$ respectively, and for the process $X_{2}$ the values were $0.08 \%, 0.06 \%$ and $0.082 \%$, respectively. The impact of the explanatory processes decreases together with the increase in the order of neighborhood and when it reaches the rank of order of neighborhood that is sufficiently high, then its impact equals zero. To provide examples, in the case of the second-order poviats neighboring the Brodnicki and Swiecki poviats, the impact of the process $X_{1}$ decreases to the level of $-0.02 \%$ and $-0.018 \%$. In the case of the process $X_{2}$, it falls to $-0.023 \%$ and $-0.02 \%$. The impact of some selected poviats of the DolnoSlaskie voivodship, Legnica and Wroclaw, and selected poviats of the Lubelskie voivodship - Bialskie and Bilgorajskie - equals approximately zero due to their too distant location from the Torun poviat, in the sense of the order of neighborhood.

${ }^{27}$ According to Table 1 , the estimates obtained for the parameters are -0.425 for the parameter $\beta_{1}$ and -0.472 for the parameter $\beta_{2}$ The actual impact of these explanatory processes in Torun (Table 2) reaches the levels of $-0.47 \%$ and $-0.52 \%$ which is caused by the additional spatial impact from the neighboring regions. The parameters estimates express the direct effect described in the work by Abreu, de Groot, and Florax (2005); the total effect is described by the direct effect as presented by LeSage and Pace (2009). 
Table 3. Impact of the change in the level of investment outlays and the number of economic subjects in Torun and Bydgoszcz on the unemployment rate in the analyzed poviats

\begin{tabular}{|c|c|c|c|c|}
\hline \multirow[b]{2}{*}{ Poviat } & \multirow[b]{2}{*}{ Voivodship } & \multicolumn{3}{|c|}{ Effect of impact } \\
\hline & & $\begin{array}{c}\text { Investment } \\
\text { outlays }\end{array}$ & $\begin{array}{c}\text { Number of } \\
\text { entities }\end{array}$ & $\begin{array}{r}\text { Total } \\
\text { effect }\end{array}$ \\
\hline Legnica & DolnoSlaskie & 0.000 & 0.000 & 0.000 \\
\hline Wroclaw & DolnoSlaskie & 0.000 & 0.000 & 0.000 \\
\hline Aleksandrowski & Kujawsko-Pomorskie & -0.097 & -0.107 & -0.204 \\
\hline Brodnicki & Kujawsko-Pomorskie & -0.028 & -0.031 & -0.059 \\
\hline Bydgoski & Kujawsko-Pomorskie & -0.127 & -0.141 & -0.268 \\
\hline $\begin{array}{l}\text { Chelminski } \\
\text { Golubsko- }\end{array}$ & Kujawsko-Pomorskie & -0.148 & -0.164 & -0.311 \\
\hline Dobrzynski & Kujawsko-Pomorskie & -0.096 & -0.106 & -0.202 \\
\hline Grudziadzki & Kujawsko-Pomorskie & -0.037 & -0.041 & -0.078 \\
\hline Inowroclawski & Kujawsko-Pomorskie & -0.119 & -0.131 & -0.250 \\
\hline Lipnowski & Kujawsko-Pomorskie & -0.034 & -0.037 & -0.071 \\
\hline Mogilenski & Kujawsko-Pomorskie & -0.034 & -0.038 & -0.072 \\
\hline Nakielski & Kujawsko-Pomorskie & -0.097 & -0.108 & -0.205 \\
\hline Radziejowski & Kujawsko-Pomorskie & -0.035 & -0.038 & -0.073 \\
\hline Rypinski & Kujawsko-Pomorskie & -0.024 & -0.026 & -0.050 \\
\hline Sępolenski & Kujawsko-Pomorskie & -0.078 & -0.086 & -0.164 \\
\hline Swiecki & Kujawsko-Pomorskie & -0.077 & -0.085 & -0.163 \\
\hline Torunski & Kujawsko-Pomorskie & -0.133 & -0.148 & -0.281 \\
\hline Tucholski & Kujawsko-Pomorskie & -0.096 & -0.107 & -0.203 \\
\hline Wabrzeski & Kujawsko-Pomorskie & -0.109 & -0.120 & -0.229 \\
\hline Wloclawski & Kujawsko-Pomorskie & -0.017 & -0.019 & -0.036 \\
\hline Zninski & Kujawsko-Pomorskie & -0.091 & -0.101 & -0.191 \\
\hline Bydgoszcz & Kujawsko-Pomorskie & -0.526 & -0.583 & -1.109 \\
\hline Grudziadz & Kujawsko-Pomorskie & -0.038 & -0.043 & -0.081 \\
\hline Torun & Kujawsko-Pomorskie & -0.529 & -0.587 & -1.116 \\
\hline Wloclawek & Kujawsko-Pomorskie & -0.017 & -0.019 & -0.036 \\
\hline Bialski & Lubelskie & 0.000 & 0.000 & 0.000 \\
\hline Bilgorajski & Lubelskie & 0.000 & 0.000 & $\mathbf{0 . 0 0 0}$ \\
\hline
\end{tabular}

Source: Authors' compilation. 
In the case of scenario 2, two columns were taken from both the matrix $S_{1}(W)$ and $S_{2}(W)$. The columns that were selected included detailed interpretations of the impact of the Torun and Bydgoszcz poviats on all the poviats considered. The results of the calculations made for scenario 2 are contained in Table 3, which presents the effects of the impact of the Torun and Bydgoszcz poviats on selected poviats. The effects of the impact concern the change in investment outlays by one unit, the change in the number of economic entities and the corresponding total effect for both explanatory processes $^{28}$.

While interpreting the results shown in Table 3 it must be emphasized that the occurring spatial impacts are related to the change in the explanatory processes in both the Torun poviat and the Bydgoszcz poviat. The fall in the unemployment rate in the two poviats, caused by the process $X_{1}$ amounts to $0.529 \%$ and $0.526 \%$ respectively. The bigger fall in the unemployment rate, if compared with scenario 1 , was impacted by the change in the explanatory processes and by the existing spatial dependence. The two poviats impact each other spatially since Torun is a first-order neighbor to Bydgoszcz and Bydgoszcz is a first-order neighbor to Torun.

Similar to scenario 1, the strength of the impact is dependent on the order of neighborhood possessed by Torun and Bydgoszcz. The strongest impact occurs in the case of the poviats being first-order neighbors to both Torun and Bydgoszcz. Examples of such poviats include Torunski, Bydgoski and Chelminski, where the impact was $-0.133 \%,-0.127 \%$ and $-0.148 \%$, respectively, for the process $X_{1}$ and, in the case of the process $X_{2},-0.148 \%$, $-0.141 \%$ and $-0.164 \%$. A weaker impact can be seen in the poviats which are first-order neighbors to Torun (or Bydgoszcz) and second-order neighbors to Bydgoszcz (or Torun). The examples are the Aleksandrowski and Tucholski poviats, where the impact is $-0.097 \%$ and $-0.096 \%$ for the process $X_{1}$ and $-0.107 \%$ and $-0.107 \%$ for the process $X_{2}$. The more distant the location of a given poviat to the Torun and Bydgoszcz poviats is, the weaker the impact. For instance, for the Mogilenski poviat that is a second-order neighbor to Torun and Bydgoszcz the impact of the explanatory processes $X_{1}, X_{2}$ decreases to $-0.034 \%$ and $-0.038 \%$. Obviously, that results from the overlapping spatial impacts which become weaker when the order of neighborhood increases. Similar to scenario 1, in scenario 2 the impact of selected poviats of the Dolnoslaskie voivodship, i.e., of Legnica and Wroclaw, and of selected poviats of the Lubelskie voivodship (Bialski and Bilgorajski) is approxi-

${ }^{28}$ Table 3 contains the results of the calculations made for the same poviats as in Table 2. The effect of the impact was computed as the aggregate of the two selected columns from the matrix $S_{1}(W)$ The effect of impact of the number of entities was computed as the aggregate of the two selected columns from the matrix $S_{2}(W)$. 
mately equal to zero due to the remote distance (in the sense of neighborhood) to Torun and Bydgoszcz.

If we compare Table 2 and Table 3, we can easily observe that in all the poviats the fall in the unemployment rate is larger than in the case of scenario 2, which is caused by the accumulation of the effects of the spatial impacts of Torun and Bydgoszcz. The scenarios presented describe the increase in the complexity of spatial impact along with the consideration of further locations in which the explanatory processes were changed. When we are faced with the actual economic phenomena, then we deal with various changes in the values of the explanatory processes for all the poviats. This is a situation when in each poviat occur, firstly, the direct effect resulting exclusively from the change in the level of the explanatory processes, and, secondly, a vast number of overlapping impacts of a weaker strength resulting from the existing spatial dependency. The use of the spatial models and the adequate interpretation of the structural parameters allow a proper description of the complex causal dependency for the economic phenomena characterized by the spatial dependency property.

\section{General Interpretation of the Structural Parameters of the Empirical SAR Model}

The matrix $S_{r}(W)$ calculated for 379 poviats and based on the estimated SAR model includes the detailed interpretations of the impact of the process $X_{r}$, and is composed of 143,641 elements. That proves the need to use the introduced measures of average impact which would allow a general interpretation of the structural parameters for spatial models that would be easy to comprehend. As concerns the set of measures introduced in this article, three measures are available and they can be applied to determine the average impact resulting from the change in the explanatory processes. The measures presented allow an easy general interpretation of the structural parameters of the model depending on the fact whether the change occurred within the researched region, in the neighboring or distant locations. The set of measures calculated on the basis of the estimation of the $S A R$ model is shown in Table 4. Taking into account the calculated measures of average impact, the general interpretation of the structural parameters of the empirical $S A R$ model can be explained as follows. An increase of one thousand zlotys in investments made per inhabitant in a selected location (any of Poland's poviats) will cause an average fall in the unemployment rate of $0.481 \%$ in the same location. The same increase will also contribute to the average fall in the unemployment rate of $0.076 \%$ in any of the first-order 
neighborhood locations selected freely and to the average fall in the unemployment rate of $0.001 \%$ in any location selected from the remaining ones. We can provide a general interpretation relative to the explanatory process $X_{2}$ in a similar way.

Table 4. Measures of average direct, indirect and induced impacts ${ }^{29}$

\begin{tabular}{lcccccc}
\hline Explanatory processes & $A_{D}$ & $A_{I}$ & $A_{R}$ & $A_{D}$ & $A_{I}$ & $A_{R}$ \\
\hline \multicolumn{3}{c}{ Mean estimates } \\
Process $X_{1}$ & -0.481 & -0.076 & -0.001 & 19.45 & 6.23 & 2.12 \\
Process $X_{2}$ & -0.533 & -0.093 & -0.002 & 23.53 & 9.45 & 3.98 \\
\hline
\end{tabular}

Source: Authors' compilation.

The material presented above illustrates the use proposed in the article of the set of measures for a general interpretation of the SAR model. In less complex cases, where the change in the level of the explanatory process occurs in a small number of locations (scenarios 1 and 2), I perceive a possibility of using the set of measures for the purposes of the obtainment of approximate values of detailed interpretations. The use of the measures of average spatial impact for the purposes of the obtainment of approximate values of detailed interpretations will be demonstrated on example of poviats selected from the Kujawsko-Pomorskie voivodship with the assumption of the earlier scenarios. Table 5 contains the order of neighborhood of the selected poviats in relation to Torun and Bydgoszcz. The choice of a specific measure for the selected region will be dependent on the order of neighborhood in relation to the poviat where the change in the explanatory process occurred. The effect of the impact resulting from the empirical SAR model and the effect obtained after the use of the three measures with the assumption of scenario 1 are presented in Table 6 . Since the change in the explanatory processes is assumed merely for one location, the Torun poviat, during the interpretation of their impact average impact measures were used only for that location. The direct impact measure $A_{D}$ was taken to determine the average impact of the change in the explanatory process in Torun on the

${ }^{29}$ Statistical significance of measures was calculated in accordance with the tips contained in a work by LeSage and Pace (2009). In order to draw inferences regarding the statistical significance of the measures of average impact a simulation can be constructed. After making a simulation, the empirical distribution of the parameters of model was obtained and then, based on it, the distribution of measures of average impact was calculated. Mean estimates and t-statistic for measures of average impact are contained in Table 4. 
process being explained in the same location. The indirect measure $A_{I}$ was applied to determine average changes in the unemployment rates in the poviats that are the first-order neighbors to Torun. The average induced impact $A_{R}$ allowed the designation of the average impact of the explanatory processes in all the remaining poviats. The effect of the impact of the explanatory processes for Torun calculated with the measures equals the value of the $A_{D}$ measure and is $-0.481 \%$ for the process $X_{2}$ and $-0.533 \%$ for the process $X_{2}$. The effect of the impact for the Torunski, Bydgoski, Chelminski and Aleksandrowski poviats, the first-order neighbors to Torun, equals the value of the measure $A_{I}$. The effect of the impact for Tucholski and Mogilenski poviats, second-order neighbors to Torun, equals the value of the measure $A_{R}$.

Table 5. Order of neighborhood in relation to Torun and Bydgoszcz for selected poviats of the Kujawsko-Pomorskie voivodship

\begin{tabular}{lcc}
\hline \multirow{2}{*}{ Poviat } & \multicolumn{2}{c}{ Order of neighborhood } \\
\cline { 2 - 3 } & Torun & Bydgoszcz \\
\hline Torun & 0 & I \\
Bydgoszcz & I & 0 \\
Torunski & I & I \\
Bydgoski & I & I \\
Chelminski & I & I \\
Aleksandrowski & I & II \\
Tucholski & II & I \\
Mogilenski & II & II \\
\hline
\end{tabular}

Source: Authors' compilation.

Table 6. Use of measures of average impact under scenario 1

\begin{tabular}{lcccc}
\hline \multicolumn{5}{c}{ Impact of explanatory processes } \\
\cline { 2 - 5 } Poviat & Investments & Economic entities & Total & Measure \\
\hline \multicolumn{2}{l}{ The effect of the impact calculated with } & use of the matrix $S_{r}(W)$ \\
Torun & -0.468 & -0.519 & & \\
Bydgoszcz & -0.055 & -0.060 & -0.987 & - \\
Torunski & -0.072 & -0.080 & -0.115 & - \\
Bydgoski & -0.055 & -0.060 & -0.152 & - \\
& & & & -
\end{tabular}


Table 6 continued

\begin{tabular}{|c|c|c|c|c|}
\hline \multirow[b]{2}{*}{ Poviat } & \multicolumn{4}{|c|}{ Impact of explanatory processes } \\
\hline & Investments & Economic entities & Total & Measure \\
\hline Chelminski & -0.074 & -0.082 & -0.155 & - \\
\hline Aleksandrowski & -0.073 & -0.081 & -0.155 & - \\
\hline Tucholski & -0.017 & -0.019 & -0.035 & - \\
\hline Mogilenski & -0.013 & -0.014 & -0.027 & - \\
\hline \multicolumn{5}{|c|}{ The effect of the impact calculated with use of the set of measures } \\
\hline Torun & -0.481 & -0.533 & -1.014 & $A_{D}$ \\
\hline Bydgoszcz & -0.076 & -0.093 & -0.169 & $A_{D}$ \\
\hline Torunski & -0.076 & -0.093 & -0.169 & $A_{I}$ \\
\hline Bydgoski & -0.076 & -0.093 & -0.169 & $A_{I}$ \\
\hline Chelminski & -0.076 & -0.093 & -0.169 & $A_{I}$ \\
\hline Aleksandrowski & -0.076 & -0.093 & -0.169 & $A_{I}$ \\
\hline Tucholski & -0.001 & -0.002 & -0.003 & $A_{R}$ \\
\hline Mogilenski & -0.001 & -0.002 & -0.003 & $A_{R}$ \\
\hline
\end{tabular}

Source: Authors' compilation.

Table 7 shows the effect of the impact resulting from the empirical $S A R$ model as well as the effect calculated with use of the measures under scenario 2. In this case, while determining the value of the effect of the impact for a poviat with use of the measures, it is necessary to consider the interpretation of the measures separately for the impact of Torun and separately for the impact of Bydgoszcz. Eventually, the aggregate of the effects resulting from the value of two measures will allow the final result to be obtained. Establishing an average impact for Torun will consist in adding up the two measures $A_{D}+A_{I}$. This is due to the fact that the change in the explanatory processes occurred in Torun, as well as Bydgoszcz, for which Torun is the first-order neighbor. In the case of determining the unemployment rate for the Bydgoszcz poviat we can observe an identical situation. Therefore, the values in Table 7 resulting from the application of the average impact measures are the same for both poviats. For the Torunski, Bydgoski and Chelminski poviats, which are the first-order neighbors both for Torun and Bydgoszcz, it is necessary to add up the same values of the measure of spatial indirect impact $A_{I}+A_{I}$. In the event that one of the poviats has the rank of order of neighborhood higher than one in relation to either Torun or Bydgoszcz, then it is necessary to use the measure of average induced impact $A_{R}$. 
Following the procedure described, the average effects for the same poviats as contained in Table 6 were determined with use of the set of measures.

Table 7. Use of the measures of average impact under scenario 2

\begin{tabular}{|c|c|c|c|c|}
\hline \multirow[b]{2}{*}{ Poviat } & \multicolumn{4}{|c|}{ Impact of explanatory processes } \\
\hline & Investments & Economic entities & Total & Measure \\
\hline \multicolumn{5}{|c|}{ The effect of the impact calculated with use of the matrix $S_{r}(W)$} \\
\hline Torun & -0.529 & -0.587 & -1.116 & - \\
\hline Bydgoszcz & -0.526 & -0.583 & -1.109 & - \\
\hline Torunski & -0.133 & -0.148 & -0.281 & - \\
\hline Bydgoski & -0.127 & -0.141 & -0.268 & - \\
\hline Chelminski & -0.148 & -0.164 & -0.311 & - \\
\hline Aleksandrowski & -0.097 & -0.107 & -0.204 & - \\
\hline Tucholski & -0.096 & -0.107 & -0.203 & - \\
\hline Mogilenski & -0.034 & -0.038 & -0.072 & - \\
\hline \multicolumn{5}{|c|}{ The effect of the impact calculated with use of the set of measures } \\
\hline Torun & -0.557 & -0.626 & -1.183 & $A_{D}+A_{I}$ \\
\hline Bydgoszcz & -0.557 & -0.626 & -1.183 & $A_{D}+A_{I}$ \\
\hline Torunski & -0.152 & -0.186 & -0.338 & $A_{I}+A_{I}$ \\
\hline Bydgoski & -0.152 & -0.186 & -0.338 & $A_{I}+A_{I}$ \\
\hline Chelminski & -0.152 & -0.186 & -0.338 & $A_{I}+A_{I}$ \\
\hline Aleksandrowski & -0.077 & -0.095 & -0.172 & $A_{I}+A_{R}$ \\
\hline Tucholski & -0.077 & -0.095 & -0.172 & $A_{I}+A_{R}$ \\
\hline Mogilenski & -0.002 & -0.004 & -0.006 & $A_{I}+A_{R}$ \\
\hline
\end{tabular}

Source: Authors' compilation.

To summarize the application of the set of measures it must be emphasized that the effect of the impact calculated for Torun, Bydgoszcz and their first-order neighbors is overstated. That overstatement results from the fact that for computing purposes all the regions are taken into account and the outskirts regions, since they have a small number of neighbors, contribute to this overstatement of the values of the measure. The measures show also the average effect of the impact, and in the case of the poviats of Torun and of Bydgoszcz, the impact resulting from the matrix $S_{r}(W)$ is weaker due to a large number of neighbors. For the poviats being the second-order neighbors lower values of impact were obtained. That is caused by the fact that the measure $A_{R}$ reflects the average impact for all the regions possessing the 
order of neighborhood higher than one. For the orders of neighborhood approximate to one, the measure provides understated results, and for the orders of neighborhood exceeding one significantly the results obtained are overstated.

Despite the errors indicated, using the introduced set of measures of average impact by a decision-maker seems to be much simpler than use of the matrix $S_{r}(W)$, which includes all detailed interpretations of the model. The result obtained is merely an approximation of the actual values of impact; however, that approximation is reflected precisely enough to be used in decision-making processes.

\section{Conclusions}

In the majority of analyses of economic phenomena the non-consideration of spatial dependency constitutes a vital cognitive error. In the case of examining the phenomenon of the unemployment rate it may be hard to accept that the change in factors in a selected region impacting the unemployment rate does not impact the unemployment level in the neighboring regions. Such a thesis is assumed while using a linear regression model. As a matter of fact, only the use of spatial models, including the SAR model, allows the consideration of the existing spatial dependency. However, using spatial models entails problems related to the interpretation of structural parameters.

That problem was given much attention in the article and the concept of detailed interpretations was distinguished for the spatial SAR model. Those interpretations, contained in the matrix $S_{r}(W)$, determine the average impact of the explanatory processes depending on the accepted locations. Due to a vast number of detailed interpretations pertinent to the model there is a need to determine the average impact that would allow a general interpretation of spatial models.

Therefore, the article discussed the measures of average spatial impact proposed by subject literature. Next, based on the considerations made, I introduced an original set of measures of average spatial impact which are complementary in their character to the already existing ones. The measures presented allow an easy and explicit interpretation of the average strength of the impact of the explanatory processes within the $S A R$ model. It must be noted that the measures introduced can be determined also for other spatial models.

The additionally proposed set of measures may be used as an approximation of detailed interpretations for spatial models. With the knowledge of the empirical form of the model and spatial weight matrix $W$, it is possible to reduce the number $n^{2}$ of detailed interpretations to three values only. It can 
be stated that the introduced set of measures allows the conducting in an easy manner of a general interpretation of structural parameters and approximate detailed interpretation of the strength of impacts of specific explanatory processes within the $S A R$ model. Therefore, average impact measures can be used as an instrument that is useful in assessing spatial impact. Also, it is useful in making decisions on establishing proper values for causal processes, which is essential from decision-makers' point of view.

\section{References}

Abreu M.H., de Groot L.H., Florax J.G.M. (2005), Space and growth: a survey of empirical evidence and methods, "Région et Développement", Vol. 21.

Anselin L. (1988), Spatial Econometrics: Methods and Models, Kluwer Academic, Dordrecht.

Anselin L., Florax. J.G.M. (1995), New Directio, $n$ in Spatial Econometrics, Springer-Verlag, Berlin Heidelberg.

Anselin L. (2003), Spatial Externalities, Spatial Multipliers, And Spatial Econometrics, "International Regional Science Review", Vol. 26.

Anselin L., Florax J.G.M., Rey S.J. (eds.), (2004), Advances in Spatial Econometrics. Methodology, Tools and Applications, Berlin, Springer-Verlag.

Arbia G. (1989), Spatial Data Configuration in Statistical Analysis of Regional Economics and Related Problems, Kluwer Academic Publisher, Dordrecht.

Arbia G. (2006), Spatial Econometrics: Statistical Foundations and Applications to Regional Convergence, Springer-Verlag, Berlin Heidelberg.

Bivand R.S., Pebesma E.J., Gómez-Rubio V. (2008), Applied Spatial Data Analyses with $R$, Springer, New York.

Cliff A.D., Ord J.K. (1973), Spatial Autocorrelation, Pion, London.

Cliff A.D., Ord J.K. (1981), Spatial Processes: Models and Applications, Pion, London.

Cressie N.A.C. (1993), Statistics for Spatial Data, Wiley \& Sons, New York.

Fischer M.M., Getis A. (eds.) (2004), Recent Developments in Spatial Analysis: Spatial Statistics, Behavioural Modelling, and Computational Intelligence, Springer-Verlag, Berlin Heidelberg.

Getis A., Mur J., Zoller H.G. (eds.) (2004), Spatial Econometrics and Spatial Statistics, Palgrave Macmillan, New York.

Griffith D.A. (1988), Advanced Spatial Statistics, Kluwer Academic Publisher, Dordrecht.

Griffith D.A. (2003), Spatial Autocorrelation and Spatial Filtering: Gaining Understanding Through Theory and Scientific Visualization, Springer-Verlag, Berlin Heidelberg.

Haining R. (1990), Spatial data analysis in the social and environmental sciences, Cambridge University Press, Cambridge.

Haining R. (2003), Spatial Data Analysis: Theory and Practice, Cambridge University Press, Cambridge. 
Kelejian H.H., Murrell P., Shepotylo O. (2008), Spatial Spillovers in the Development of Institutions, Working Papers

Klaassen L.H., Paelinck H.P., Wagenaar S. (1979), Spatial Systems: a general introduction, Saxon House, Farnborough.

LeSage J., Pace R.K. (eds.) (2004), Advances in Econometrics: Spatial and Spatiotemporal Econometrics, Elsevier Ltd, Amsterdam.

LeSage J., Pace R.K. (2009), Introduction to Spatial Econometrics, FL: Chapman \& Hall/CRC, Boca Raton.

Paelinck J.H.P., Nijkamp P. (1975), Operational theories and method in regional analysis, Saxon House, Farnborough.

Paelinck J.H.P., Klaassen L.H. (1979), Spatial Econometrics, Saxon House, Farnborough.

Ripley B.D. (1981), Spatial Statistics, Wiley \& Sons, New York.

Schabenberger, O., Gotway C.G. (2005), Statistical Methods for Spatial Data Analysis, Chapman \& Hall/CRC, Boca Raton.

Ward M.D., Kristian S.G. (2008), Spatial Regression Models, CA: Sage, Thousand Oaks. 